- The training and education of Professionals Complementary to Dentistry (PCDs) has received increasing attention following changes in the requirements for registration and the permitted roles of PCDs.

- A review of training and education programmes for PCDs throughout the world was undertaken.

- Programmes of training for PCDs can be said to vary along four dimensions: the role which the learner trains for; the nature of the qualifications required for entry to the training pathway; the method of training; the location of training. - An educational model of the training and education of PCDs is proposed based upon these four dimensions, which seeks to maximise the benefits of the elements whilst minimising the disadvantages.

\title{
An appraisal of options of the training and education of Professionals Complementary to Dentistry
}

\author{
J. T. Newton, ${ }^{1}$ K. Jones, ${ }^{2}$ P. D. Newton ${ }^{3}$ and D. E. Gibbons ${ }^{4}$
}

The training and education of Professionals Complementary to Dentistry (PCDs) has become a topic of close scrutiny and much debate in the recent past, particularly with the introduction of enhanced duties and compulsory registration of some groups. This paper will describe the background to, the conduct of and the findings from a workshop held to explore innovative approaches to the education and training of PCDs in the United Kingdom. Existing systems of training and education of PCDs will be reviewed through the exploration of published literature and through the collection of primary data from interviews with key personnel both in the UK and internationally. An option appraisal is described which identified the elements common to all training approaches, used the elements as the basis for innovative training options, and explored the perceived advantages and disadvantages of each option through focus group discussions at a one-day workshop. A model for the training and education of PCDs is described that maintains existing PCD roles, but offers a broader range of entry points to training, settings for training and that builds upon existing skills to facilitate progression through the PCD roles.

\section{BACKGROUND}

In the UK, and the rest of the world, a number of factors have directed attention to the need to develop a workforce comprising skilled professionals with specific and complementary roles within the dental team. Among these factors have been the dramatic changes in the pattern and distribution of the need for, and provision of, dental health services. In the UK, for example, the Adult Dental Health Survey ${ }^{1}$ found that the number of dentate adults with missing teeth had fallen, and that the population had fewer missing teeth and more sound and untreated teeth than was prevalent 20 years before.

\footnotetext{
1*Professor of Psychology as applied to dentistry ${ }^{2}$ Specialist Registrar, ${ }^{3}$ Research Assistant, ${ }^{4}$ Emeritus Professor ,Oral Health Services Research and Dental Public Health, GKT Dental Institute, King's College London ${ }^{*}$ Correspondence to Professor J.T. Newton, Oral Health Services Research and Dental Public Health, GKT Dental Institute, King's College London, Caldecot Road, London, SE5 9RW

Email: tim.newton@kcl.ac.uk
}

\section{Refereed Paper}

Received 01.07.03; Accepted 07.04.04

doi: $10.1038 /$ sj.bdj.4812254

(๑) British Dental Journal 2005; 198: 499-502
The average number of decayed teeth in the adult population also fell significantly during this period. Although the average number of filled teeth had remained fairly constant, the distribution had changed quite markedly towards older adults having more filled teeth than people of a similar age 20 years previously, whilst the reverse was true for younger adults. The Adult Dental Health Survey concluded that oral health indicators illustrated a need to reconsider the way in which services are delivered including "the development of a greater role for PCDs...[which]... may offer some solutions for managing this changed environment.' In addition, in response to the House of Commons Health Committee report entitled Access to NHS Dentistry, Lord Philip Hunt announced the National Dental Workforce review. This review, the first of its kind since 1987, anticipated that it would:

- identify the size and nature of the dental workforce required to deliver the strategy outlined in Modernising NHS Dentistry ${ }^{2}$
- provide the foundation for regular workforce planning at national and local levels - review the quotas for dental school intakes - consider measures to modernise the education and training of dentists and Professionals Complementary to Dentistry.

It is the last outcome that this article will address. The overall aim of this project was therefore to identify the feasibility of alternative approaches to the training and education of Professionals Complementary to Dentistry. In order to achieve this aim, the following objectives were identified:

a To review the current training and education of PCDs in the United Kingdom and throughout the world

b To identify the underlying key educational approaches underlying models of training and education for PCDs

c To identify the advantages and disadvantages of the educational approaches identified in (b) from the perspective of individuals involved in the training, education and employment of PCDs in the UK 


\begin{tabular}{|l|l|}
\hline $\begin{array}{l}\text { Option A } \\
\text { Linear courses for different professionals } \\
\text { Based in centres of further/higher education } \\
\text { Formal entry points } \\
\text { Leading to qualification as specific PCD }\end{array}$ & $\begin{array}{l}\text { Option B } \\
\text { Skills escalator } \\
\text { Based in university/clinical centres } \\
\text { Formal entry points } \\
\text { Leading to qualification as specific PCD }\end{array}$ \\
\hline $\begin{array}{l}\text { Option C } \\
\text { Apprenticeship model of training } \\
\text { Based in practice and accredited by central agency } \\
\text { Informal entry point } \\
\text { Leading to qualification as specific PCD }\end{array}$ & $\begin{array}{l}\text { Option C } \\
\text { Skills escalator } \\
\text { Informal entry point } \\
\text { Leading to qualification as dentist }\end{array}$ \\
\hline
\end{tabular}

Fig. 1 Four theoretical options for training of Professionals Complementary to Dentistry used in workshop session. The four options are independent, differing along the dimensions identified in Phase 1 of the research.

d To ask individuals involved in the training, education and employment of PCDs in the UK to devise a model for training and education of PCDs in the UK.

\section{METHODS}

There were three distinct phases of this project.

\section{Phase 1}

The first phase reviewed existing arrangements for the education and training of PCDs, both within the United Kingdom and throughout the world through a literature review of academic journals (dental, medical and educational), reports and websites. Literature searches were conducted using the following phrases as key words and free text searches: 'dental personnel', 'Dental Therapist', 'Dental Hygienist', 'Dental Nurse', 'Dental Technician', 'Dental Auxiliary', 'Professional Complementary to Dentistry', 'Professionals Complementary to Dentistry'. 'Oral and Maxillofacial Technologist'. Starting from known sources of information which made recommendations on the training and education of PCDs, the authors searched the references of the report for further information. Web pages of university dental schools and dental hospitals were identified throughout the world and searched for information on the training of PCDs. For all sources of information, names of key personnel were identified for possible interviewing.

Key personnel in the training of PCDs and dentists were identified from personal contact and from the review of literature, reports, web pages and interviews. In addition, in order to explore the range of teaching approaches possible in team working, individuals from other groups where team working is required were interviewed. Interviewees were asked to identify any additional individuals who they thought would be useful contacts for the project. These were then interviewed wherever possible, following the technique of 'snowball' sampling. ${ }^{3}$ A series of openended questions were written asking for information on the education and training of the different PCD groups and were administered either in person, by phone or email. The data were qualitative. In total 52 sets of questions were administered by post and by email or via face to face or telephone interviews. Thirty-one were administered in the UK and 21 were international. The response rate was 70\%.

The analysis of these data sought to identify the common elements along which the methods and approaches to training and education of PCDs differed both across PCD roles within a single country and across countries. An inductive approach to data analysis was adopted. ${ }^{4}$ The data were analysed in two ways. First, the common themes or elements, along which the different approaches to education and training of dental personnel varied, were explored and developed into a conceptual model by two of the authors (both experienced in qualitative methods; one was an expert in educational approaches). The four elements identified are listed in the Phase 1 results section. Four theoretical options for the training and education of PCDs were then devised based on these elements. These options were devised by the project team to incorporate the dimensions of the elements identified, whilst balancing the perceived feasibility of the approach. These four theoretical models are given in Figure 1.

\section{Phase 2}

The second phase involved the appraisal of the four options by key personnel involved in the training of PCDs, dental practitioners, other healthcare workers and those involved in general education. A one-day conference was held at a venue in London. Thirty-four delegates were identified from the key UK-based individuals involved in the training and education of PCDs (and other professions where team work is involved) in Phase 1 of the project and invited to attend the conference, of whom 26 were able to attend. The delegates represented a broad range of professional groups (dentists, PCDs and educators) and a variety of involvement (including commissioners of dental education and services, those directly involved in training and education, and users - that is PCDs themselves - among others). The conference was based on two workshop discussion sessions. After an introduction to the research in which the findings of the literature review and the interviews were presented, and an explanation of the conceptual model was given, delegates were split into four working groups. All four groups were facilitated by professional group facilitators who were experienced educators. Each group was given one of the four options identified

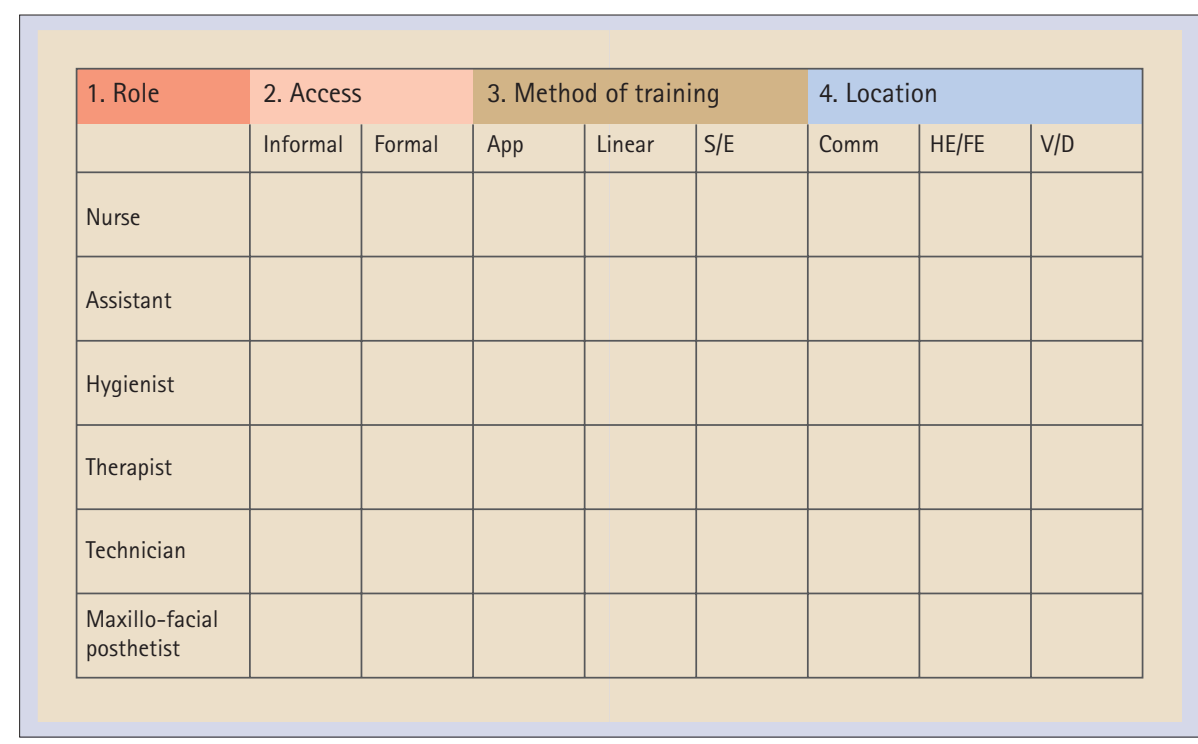

Fig. 2. Elements of the conceptual model of training and educating PCDs. Key: App = apprentice; S/E = skills escalator; Comm $=$ community; $\mathrm{HE} / \mathrm{FE}=$ higher/further education; $\mathrm{V} / \mathrm{D}=$ virtual/distance. 


\section{Roles: Maintain existing roles} Access: Formal

Method: Skills escalator Location: Various

Option one is built on a progressive modular programme of training and education. Entry to the training pathway would be through formal assessment, which would test a range of skills and attributes, for example, literacy, numeracy, problem solving skills, communication, dexterity etc. All learners would then undertake the same series of core competencies. Following this, there would be further modular training, each worth a number of 'points', leading to qualification as a specific PCD or dentist. A key feature of the training is that there would be opportunity to build on prior learning and opportunity to move from PCD to PCD to dentist by gaining a certain number of 'points'

Modules would also be transferable across the care professions. Entry at different points would be an option as prior learning and work experience would be taken into account. Training would be flexible, allowing for career breaks and part time learning.

Running through the programme would be a series of career consultations to ensure that training is appropriate to personal needs.

\section{Group Two}

Access: Forma

Method: Skills escalator

Location: Various

Option two represents a more formal approach to training. Access to training would only be available to those aged over 18 years. Pre-training would be available within schools for those below this age. The first 18 months of training would be workplace based and incorporate either block or day release to an institute of education. Following this, training would separate into two pathways, the first for those directly involved in patient care and the second for those working remote from the patient. Training would lead to a specific PCD. Core clinical skills would be learnt followed by clinical modules, which would be competency based. This stage would be over the period of one year and would be formally assessed. The outcome would be an extended duties dental nurse.

A further two years of training could be undertaken leading to other specific PCDs. On completion of these two years, a vocational period of training would be mandatory. Further learning could be undertaken leading to degree level. Opportunities for undertaking teaching and research would be available to those reaching degree level. There would also be opportunity to undertake further training to become a therapist or dentist.

There would be multiple access points, which would take into account educational achievement and prior work experience.

\section{Group Three}

Roles: Maintain existing roles Access: Informa

Method: Skills escalator Location: Various

Access to option three would be universal. Students would attain elements of training that would build towards a specific dental role. Core elements would be common to all roles, with additional elements for specific roles. Incentives would be offered to ensure appropriate workforce development. Training would be flexible in terms of time scale and would involve team working. Formal qualifications would be the end point; it would be possible to return for further training at a later date.

\section{Group Four}

\section{Roles: Maintain existing roles}

\section{Method: Skills escalator}

Location: Various

Group four sought to redefine competences and creating new roles. It was envisaged that training would be progressive and modular with the curriculum being competency based. Modules would be transferable across care professionals.

The teaching method would be designed to meet learner needs and therefore could be based either within the community or in a formal educational establishment, or a combination of both. Flexibility would be a key issue to accommodate differing personal circumstances.

Access to the course would be informal and open and training could be accessed at different points. Assessment of training would combine informal and formal assessments based on a range of criteria.

A regionally based dental education advisory service would be developed as part of a care professional education centre

Fig. 3 'Ideal' models of the training and education of Professionals Complementary to Dentistry identified by workshop participants

from Phase 1 to study and asked to discuss the advantages and disadvantages of that particular training option (Fig. 1). The results of the discussion were summarised and then fed back to the rest of the delegates. A second session was then held in which the delegates were split into the same four groups and asked to devise an 'ideal' training and education option based on the elements of the conceptual model. Again, the results were reported back to all the delegates at the end of the session.

\section{Phase 3}

In the final phase of analysis the research team drew together the workshop findings and the findings from Phases 1 and 2 to produce an 'ideal' programme of training with identified advantages and disadvantages. The advantages and disadvantages were taken from those identified by workshop participants.

\section{RESULTS}

Phase 1

Using data from the survey of both UK and international training of PCDs, a conceptual model incorporating four common elements within the training of PCDs was identified by inductive analysis. ${ }^{4}$

Element 1: the role into which an individual trains. For example, in the UK, roles include: Dental Nurse, Dental Therapist, Dental Hygienist and Dental Technician amongst others. For example, in Fiji, there is an additional class of PCD, a Dental Assistant, who is in-house trained and has no formal qualification; Dental Nurses are rare in France with dentists working alone; and in Scandinavian countries there are large numbers of Dental Hygienists providing preventive input. The United States does not have a recognised Dental Therapist workforce.

Element 2: access to the training pathway. This may require formal entry points such as 'A' levels, or may be less formal; for example training as part of the job.

Element 3: the method of training. Training may take place as an apprenticeship, or as part of a course. Courses may be organised as linear units with a single course for each role, or as a 'skills escalator' where completion of training in one role acts as the basis of the training for the other roles.

Element 4: the training location. Training may be based in community settings (for example dental practices) or institutes of further or higher education. Training may also involve virtual or distance learning options. Community setting here is not meant to refer solely to the Community Dental Service but covers settings outside the formal education system.

These elements were then developed into a conceptual model of training and education. The elements of the conceptual model are shown in Figure 2. The conceptual model simply lists the elements with their sub-categories.

\section{Phase 2}

Table 1 summarises the advantages and disadvantages of the various elements of the conceptual model developed in Phase 1, as identified by the workshop participants.

\section{Phase 3}

The four groups identified two different 'ideal' approaches. These are summarised in Figure 3. All four groups suggested a model which maintained existing roles, suggested a skills escalator approach and proposed that a wide variety of training and education locations should be available. Two groups proposed formal entry points, two informal. By deduction from Table 1 the advantages and disadvantages of this approach are: 


\begin{tabular}{|c|c|c|c|c|c|c|c|c|}
\hline & \multicolumn{2}{|l|}{ Access } & \multicolumn{3}{|l|}{ Method } & \multicolumn{3}{|l|}{ Location } \\
\hline & Informal & Formal & Apprentice & Linear & Skills escalator & Community & $\mathrm{HE} / \mathrm{FE}$ & Virtual/Distance \\
\hline \multirow[t]{4}{*}{ Advantages } & $\begin{array}{l}\text { Increased } \\
\text { flexibility }\end{array}$ & Cheaper & $\begin{array}{l}\text { Increased practical } \\
\text { skills }\end{array}$ & Focused & Transferable skills & $\begin{array}{l}\text { Increased team } \\
\text { working }\end{array}$ & Cheaper & \\
\hline & $\begin{array}{l}\text { Increased } \\
\text { access }\end{array}$ & & $\begin{array}{l}\text { Matching skills } \\
\text { to job }\end{array}$ & $\begin{array}{l}\text { Employer knows } \\
\text { what they are } \\
\text { getting }\end{array}$ & $\begin{array}{l}\text { Easier workforce } \\
\text { planning }\end{array}$ & Increased access & $\begin{array}{l}\text { Work with other } \\
\text { disciplines }\end{array}$ & \\
\hline & & & & Flexible training & $\begin{array}{l}\text { Facilitates lifelong } \\
\text { learning }\end{array}$ & $\begin{array}{l}\text { Standardised } \\
\text { learning outcomes } \\
\text { (Clinical Governance) }\end{array}$ & $\begin{array}{l}\text { Research } \\
\text { opportunities }\end{array}$ & \\
\hline & & & & Career progression & $\begin{array}{l}\text { Helps recruitment } \\
\text { and retention }\end{array}$ & & & \\
\hline \multirow[t]{4}{*}{ Disadvantages } & $\begin{array}{l}\text { so research } \\
\text { and } \\
\text { evaluation }\end{array}$ & $\begin{array}{l}\text { Excludes } \\
\text { non-qualified }\end{array}$ & $\begin{array}{l}\text { Infrastructure } \\
\text { not available }\end{array}$ & $\begin{array}{l}\text { No cross role } \\
\text { exposure }\end{array}$ & $\begin{array}{l}\text { Threat to } \\
\text { professional status }\end{array}$ & Quality standards & Limited places & $\begin{array}{l}\text { No research } \\
\text { and } \\
\text { evaluation }\end{array}$ \\
\hline & & $\begin{array}{l}\text { Reduces access } \\
\text { because of } \\
\text { entry point }\end{array}$ & $\begin{array}{l}\text { How to maintain } \\
\text { standards }\end{array}$ & Role oriented & $\begin{array}{l}\text { Threat to dental } \\
\text { schools }\end{array}$ & $\begin{array}{l}\text { No research and } \\
\text { evaluation }\end{array}$ & $\begin{array}{l}\text { Theory/practice } \\
\text { gap }\end{array}$ & \\
\hline & & & $\begin{array}{l}\text { NVQ needs basic } \\
\text { qualification }\end{array}$ & & $\begin{array}{l}\text { No research and } \\
\text { evaluation }\end{array}$ & & $\begin{array}{l}\text { Geographically } \\
\text { limited access }\end{array}$ & \\
\hline & & & & & & & Hierarchical & \\
\hline
\end{tabular}

\section{Advantages:}

- modular

- builds on prior learning

- career progression

- transferable skills

- career counselling

- entry criteria test a range of competencies

- prior work experience valued

- workplace based

- career progression

- universal access

- appropriate workforce development

- flexible training

- team training

- re-entry possible

- community experience

- educational advice available

- informal access

- flexible access

- transferable modules

- competency based.

Disadvantages:

- formal entry point (if formal entry points)

- long time frame to qualify as dentist/ therapist

- hierarchical

- excludes entry from those with few formal qualifications (if formal entry points)

- role oriented

- threat to professional status

- infrastructure not available.

\section{CONCLUSIONS}

The training and education of PCDs is an important issue for dental education. Currently training needs are uncertain and a coherent and standardised approach to training and education will ensure the quality of the individuals' learning experience. The findings of this project suggest that training and education of PCDs should be based on a skills escalator approach incorporating flexibility in roles. Entry should be inclusive facilitating recruitment of individuals with few formal qualifications. The outcome of training and education should be achieving competence.$^{5}$

The main problem of such an approach would be the lack of infrastructure for training in community/practice settings as many are single surgery premises. To start addressing these issues, Workforce Development Confederations, who now have responsibility for training and education of the NHS workforce, jointly working with Primary Care Trusts could link in with initiatives such as NHS Local Improvement Finance Trusts (LIFT).

Within the workshop, there were some delegates who proposed that separate roles for dental healthcare staff were not maintained but that all dental personnel were entitled 'Dental Health Workers' and were qualified at different levels. However this was not a consensus view, the members of the workshop felt this was too ambitious a change and suggested that existing PCD roles were maintained in their proposals for the training pathways.

More research and evaluation is needed on the training and education of PCDs. Several Workforce Development Confederations now have project workers specifically looking at the training requirements of PCDs, though it is not known to what extent their findings will allow the statement of rigorous principles of training. Previous research has been conducted exploring the cost-effectiveness of employing PCDs, and this research is summarised by Galloway et al. ${ }^{6}$ There remains little research into the effectiveness of teaching approaches for this group.

The authors would like to acknowledge their gratitude to former Chief Dental Officer, Dame Margaret Seward, who supported the research described in this report. We also thank the workshop participants for their invaluable contribution.

1. Kelly M, Steele J, Nuttall N, Bradnock G, Korris J, Nunn J, Pine C, Pitts N, Treasure E, White D. Adult Dental Health Survey: Oral Health in The United Kingdom 1998. London: The Stationary Office, 2000.

2. Department of Health. Modernising NHS Dentistry Implementing the NHS Plan. London, 2000.

3. Bowling A. Research methods in health: investigating health and health services. Oxford: OUP, 1997. pp 337-338.

4. Silverman D. Interpreting qualitative data. London: Sage, 2001.

5. General Dental Council. Developing the dental team: curricula frameworks for registrable qualifications for Professionals Complementary to Dentistry (PCDs). London, 2003.

6. Galloway J, Gotham J, Lambert M, Richards D, Russel I, Russell D, Welshman J. Skills-mix in dentistry: $A$ systematic review. http://www.dh.gov.uk [accessed 26 February 2004.] 